\section{Pertussis Vaccine for Adolescents and Young Adults}

Advisory Committee on Vaccines and Immunization Practices (ACVIP) of Indian Academy of Pediatrics (IAP) has revised recommendations regarding primary immunization of children; whole cell pertussis vaccine is recommended in place of acellular pertussis vaccine. It has also recommended Tdap during pregnancy in place of Td or TT [1].

Under section 'Recommendations for adolescents and adults' it is stated that immunity against pertussis following primary booster $\mathrm{wP} / \mathrm{aP}$ vaccination wanes over the next 4-12 years. The guidelines therefore recommends offering Tdap vaccine instead of $\mathrm{Td} / \mathrm{TT}$ vaccine to all children/adolescents/adults who can afford it.

In the industrialized countries, vaccines are provided either by the government or under the medical insurance schemes. In our country, cost of vaccines (not included in national schedules) is borne by the people. Adolescents and young adults belonging to low economic groups are more prone to get pertussis infection because of overcrowding but may not be able to afford currently available Tdap vaccine. An infected person spreads the infection even before developing the symptoms of the disease himself/herself. Thus, this section of the society needs to be provided protection against pertussis so that young children and old people in the community who come in their close contact are not exposed to pertussis infection. IAP should urge the government of India to subsidize Tdap or provide it through national programs.

YASh PAUL

A-D-7, Devi Marg, Bani Park, Jaipur-302016 dryashpaul2003@yahoo.com

\section{REFERENCE}

1. Vashishtha VM, Bansal CP, Gupta SG. Pertussis vaccine: position paper of Indian Academy of Pediatrics (IAP). Indian Pediatr. 2013; 50:1001-8. 